\title{
Comparison of the Calculated Drought Return Periods Using Tri-variate and Bivariate Copula Functions under Climate Change Condition
}

\author{
Elahe Motevali Bashi Naeini ${ }^{1}$, Ali Mohammad Akhondali ${ }^{1}$, Fereydoun Radmanesh ${ }^{1}$, \\ Jahangir Abedi-Koupai ${ }^{2}$, and Shahrokh Soltaninia ${ }^{3}$ \\ ${ }^{1}$ Shahid Chamran University of Ahvaz \\ ${ }^{2}$ Isfahan University of Technology College of Agriculture \\ ${ }^{3}$ University of Hertfordshire
}

January 5, 2021

\begin{abstract}
Concerning the various effects of climate change on intensifying extreme weather phenomena all around the world, studying its possible consequences in the following years has attracted the attention of researchers. As the drought characteristics identified by drought indices are highly significant in investigating the possible future drought, the Copula function is employed in many studies. In this study, the two- and three-variable Copula functions were employed for calculating the return period of drought events for the historical, the near future, and the far future periods. The results of considering the two- and three-variable Copula functions were separately compared with the results of the calculated Due to the high correlation between drought characteristics, bivariate and trivariate of Copula functions were applied to evaluate the return periods of the drought. The most severe historical drought was selected as the benchmark, and the drought zoning map for the GCM models was drawn. The results showed that severe droughts can be experienced, especially in the upper area of the basin where the primary water resource is located. Also, the nature of the drought duration plays a decisive role in the results of calculating the return periods of drought events.
\end{abstract}

\section{Hosted file}

Manuscript.dot available at https://authorea.com/users/387350/articles/502481-comparison-ofthe-calculated-drought-return-periods-using-tri-variate-and-bivariate-copula-functionsunder-climate-change-condition 